\title{
AN APPROXIMATION THEOREM FOR SEMI-GROUPS OF OPERATORS
}

BY P. L. BUTZER AND H. G. TILLMANN

Communicated by Nathan Jacobson, January 26, 1960

Let $X$ be a real or complex Banach space with elements having norm $|f|$, let $E(X)$ be the algebra of bounded linear transformations of $X$ into itself and $\{T(t)\}$ a one-parameter semi-group in $E(X)$ of class $\left(1, C_{1}\right)$ :

(i) $T(t) \in E(X)$ for $t \in[0, \infty), T(0)=I$ (identity).

(ii) $T(s+t)=T(s) T(t)$ for $s, t \in[0, \infty)$.

(iii) $\lim _{t \rightarrow+0}\left|(1 / t) \int_{0}^{t} T(\tau) f d \tau-f\right|=0$ for all $f \in X$. $T$.

(iv) $\int_{0}^{1}\|T(\tau)\| d \tau<\infty$, where $\|T\|$ denotes the norm of the operator

The infinitesimal operator of a semi-group $\{T(t)\}$ is the linear transformation $A$ defined by

$$
A f=\lim _{t \rightarrow+0} \frac{T(t)-I}{t} f
$$

for all $f$, for which the limit exists (in the norm topology). It is easy to verify that for all $f \in D\left(A^{p}\right)$, where $D\left(A^{p}\right)$ is the domain of the iterated operator $A^{p}=A \cdot A^{p-1}$,

$$
\frac{d^{p}}{d t^{p}} T(t) f=T(t) A^{p} f=A^{p} T(t) f, \quad t \geqq 0 .
$$

If $f \in D\left(A^{p}\right)$ we have the generalized Taylor's formula

$$
T(t) f-\sum_{k=0}^{p-1} \frac{t^{k}}{k !} A^{k} f=\frac{1}{(p-1) !} \int_{0}^{t}(t-\tau)^{p-1} T(\tau) A^{p} f d \tau .
$$

It is our object to approximate $T(t) f$ for $f \in D\left(A^{p-1}\right)$ by the Taylorpolynomial $\sum_{\substack{k=0 \\ k=0}}^{p-1}\left(t^{k} / k !\right) A^{k} f$, giving:

Theorem. Let $\{T(t)\}$ be a semi-group of class $\left(1, C_{1}\right), f_{0} \in D\left(A^{p-1}\right)$. (a) If

$$
\liminf _{t \rightarrow+0}\left|\frac{p !}{t^{p}}\left(T(t)-\sum_{k=0}^{p-1} \frac{t^{k}}{k !} A^{k}\right) f_{0}-g_{0}\right|=0,
$$

then $f_{0} \in D\left(A^{p}\right)$ and $A^{p} f_{0}=g_{0}$. If

$$
\liminf _{t \rightarrow+0}\left|\frac{p !}{t^{p}}\left(T(t)-\sum_{k=0}^{p-1} \frac{t^{k}}{k !} A^{k}\right) f_{0}\right|=0,
$$


then $T(t) f_{0} \equiv \sum_{k=0}^{p-1}\left(t^{k} / k !\right) A^{k} f_{0}$.

$$
T(t) f_{0}-\sum_{k=0}^{p-1} \frac{t^{k}}{k !} A^{k} f_{0}=o\left(t^{p-1}\right) .
$$

(c) If $X$ is reflexive and

$$
\liminf _{t \rightarrow+0}\left|\frac{p !}{t^{p}}\left(T(t)-\sum_{k=0}^{p-1} \frac{t^{k}}{k !} A^{k}\right) f_{0}\right|
$$

is finite, then $f_{0} \in D\left(A^{p}\right)$ and

$$
A^{p} f_{0}=\lim _{t \rightarrow+0} \frac{p !}{t^{p}}\left(T(t)-\sum_{k=0}^{p-1} \frac{t^{k}}{k !} A^{k}\right) f_{0} .
$$

In case $p=1$, resp. $p=2$ in part (b), the above theorem is essentially identical with a result contained in Hille and Phillips [3, p. 326], parts (a) for $p=1$ and (b) for $p=2$ being due to Hille [2, p. 323] and part (c) for $p=1$ to Butzer [1]. We remark that de Leeuw [4] has considered the approximation by adjoint semi-groups so as to give results for part (c) (with $p=1$ ) in the case of nonreflexive Banach spaces.

SKETCH OF PROOF. Fundamental is the identity

$$
\frac{1}{s} \int_{0}^{s} T(\tau) B_{t}^{p} f d \tau=\frac{T(s)-I}{s} \int_{0}^{t} p \frac{\tau^{p-1}}{t^{p}} B_{\tau}^{p-1} f d \tau
$$

where

$$
B_{t}^{p} f=\frac{p !}{t^{p}}\left(T(t)-\sum_{k=0}^{p-1} \frac{t^{k}}{k !} A^{k}\right) f .
$$

In the limit $s \rightarrow+0$ we get

$$
B_{t}^{p} f=\int_{0}^{t} p \frac{\tau^{p-1}}{t^{p}} B_{\tau}^{p-1} A f d \tau,
$$

which gives by induction on $p$ that $B_{t}^{p} f=A^{p} f+o(1)$ for $f \in D\left(A^{p}\right)$ which is equivalent to (b). Under the hypothesis of (a) we obtain from $(*)$

$$
\begin{aligned}
\left|\frac{T(s)-I}{s} A^{p-1} f_{0}-\frac{1}{s} \int_{0}^{s} T(\tau) g_{0} d \tau\right| \\
\leqq \liminf _{t \rightarrow+0}\left|\frac{1}{s} \int_{0}^{s} T(\tau)\left(B_{t}^{p} f_{0}-g_{0}\right) d \tau\right|=0 .
\end{aligned}
$$

giving the result (a). 
Under the hypothesis of (c) there exists a sequence $t_{\nu} \rightarrow+0$ such that $B_{t \nu}^{p} f_{0}$ is weakly convergent to an element $g_{0}$. Then also $(1 / s) \int_{0}^{s} T(\tau) B_{t_{\nu}}^{p} f_{0} d \tau$ converges weakly to $g_{0}$ and the relation $\left({ }^{*}\right)$ can be used to show that

$$
\frac{T(s)-I}{s} A^{p-1} f_{0}=\frac{1}{s} \int_{0}^{s} T(\tau) g_{0} d \tau \rightarrow g_{0}=A^{p} f_{0} .
$$

These results have various applications to the solutions of partial differential equations, e.g. the heat equation. The proofs of these and further results will appear elsewhere.

\section{REFERENCES}

1. P. L. Butzer, Über den Grad der Approximation des Identitätsoperators durch Halbgruppen von linearen Operatoren und Anwendungen auf die Theorie der singulären Integrale, Math. Ann. vol. 133 (1957) pp. 410-425.

2. E. Hille, Functional analysis and semi-groups, Amer. Math. Soc. Colloquium Publications, vol. 31, New York, 1948.

3. E. Hille and R. S. Phillips, Functional analysis and semi-groups, rev. ed., New York, 1957.

4. $\mathrm{K}$. de Leeuw, On the adjoint semi-group and some problems in the theory of approximation, Math. Z. vol. 73 (1960).

The Technical University of Aachen and

UNIVERSITY OF HEIDELBERG 